\title{
PROCESSO AVALIATIVO UTILIZADO PELOS PROFESSORES DO ENSINO MÉDIO NAS AULAS DE EDUCAÇÃO FÍSICA DA REDE ESTADUAL DE ENSINO DE SANTA ROSA DO SUL/SC
}

http://dx.doi.org/10.5902/2318133835180

\author{
Leonan Peres Santana ${ }^{1}$ \\ Robinalva Ferreira ${ }^{2}$
}

\begin{abstract}
Resumo
Neste texto tem-se como objetivo analisar o processo avaliativo utilizado pelos professores de Educação Física com os estudantes do ensino médio da rede estadual de ensino de Santa Rosa do Sul/SC. O estudo foi desenvolvido por meio de pesquisa de campo com abordagem qualitativa. Os principais resultados acerca do processo de avaliação foram: dentre os capítulos do PPP da instituição apenas três instrumentos avaliativos são citados; quanto ao conhecimento dos estudantes acerca da avaliação percebemos que há um entendimento básico; aa auto-avaliação é utilizada apenas por um dos professores; quanto aos critérios avaliativos identificamos que são definidos a partir de documentos como PCNs e Base Nacional Curricular.

Palavras-chave: sistema avaliativo; avaliação; auto-avaliação; ensino médio.
\end{abstract}

\section{EVALUATION PROCESS USED BY TEACHERS OF MIDDLE SCHOOL IN THE LESSONS OF PHYSICAL EDUCATION OF THE STATE NETWORK OF TEACHING OF SANTA ROSA DO SUL/SC}

\begin{abstract}
The objective of this article was to analyze the evaluation process used by Physical Education teachers with the high school students of the Santa Rosa do Sul State School of Education. The study was developed through field research with a qualitative approach. The main results about the evaluation process were: among the institution's PPP chapters, only three evaluation instruments are cited; as for the students' knowledge about the evaluation, we realize that there is a basic understanding; the self-assessment is used only by one of the teachers; regarding the evaluative criteria we identify that are defined from documents such as PCNs and National Curricular Base. Key-words: evaluation system; evaluation; self-evaluation; high school.
\end{abstract}

\footnotetext{
1 Universidade do Extremo Sul Catarinense, Brasil. E-mail: leonanperess@hotmail.com.

2 Universidade do Extremo Sul Catarinense, Brasil. E-mail: rfe@unesc.net.

Regae: Rev. Gest Aval. Educ.

Pub. contínua 2019

p. $1-15$
} 


\section{Introdução}

1 avaliação faz parte do processo educativo no sentido de acompanhar o ensino e a aprendizagem, verificando se os objetivos traçados foram alcançados, diagnosticando a apreensão do conhecimento pelos estudantes, analisando as metodologias de ensino utilizadas pelos professores, replanejando de acordo com o feedback da avaliação, ou seja, vai muito além de cumprir a legislação e de promover ou reter o estudante.

Sendo assim, é de responsabilidade do professor reconhecer as capacidades, avanços e dificuldades de seus estudantes no aprendizado e realizar as mudanças necessárias para a concretização dos objetivos. Porém a avaliação é tratada por muitos professores como mecanismo de autoritarismo, ameaçando os estudantes para que estudem: "Quando o professor sente que seu trabalho não está surtindo o efeito esperado, anuncia aos alunos: "Estudem! Caso contrário, vocês poderão se dar mal no dia da prova" (Luckesi, 2001, p. 19). Essa abordagem da avaliação desvirtua suas funções, pois a utiliza para manter a ordem e a disciplina da turma, causando um estereótipo e perda para o processo de ensino e aprendizagem, inibindo os estudantes.

Muitos estudos têm sido realizados sobre a avaliação, mas pouco relacionado à disciplina de Educação Física e menos ainda na cidade de Santa Rosa do Sul/SC.

A partir dessas delimitações emergiu a problemática deste estudo: como os professores de Educação Física avaliam os estudantes do ensino médio de uma escola da rede estadual de ensino de Santa Rosa do Sul/SC?

\section{Trajetória metodológica}

O presente estudo foi desenvolvido por meio de uma pesquisa de campo. O lócus da pesquisa foi uma escola da rede estadual de ensino de Santa Rosa do Sul/SC, tendo em vista que o município possui apenas uma instituição com o ensino médio.

A escola é constituída por equipe diretiva: um diretor, dois assessores, três assistentes de direção e dois técnicos pedagógicos; corpo docente: composto por 66 professores, sendo três de Educação Física; 471 estudantes da educação básica, sendo 237 do ensino médio em 9 turmas, no período matutino e noturno. A escola possui espaço para a prática da Educação Física tendo ginásio, quadra coberta e uma quadra de vôlei de areia, porém os materiais são escassos e pouco diversos.

Os dados foram coletados por meio questionário para professores de Educação Física do ensino médio, grupo focal com estudantes e análise do PPP da escola. Esta análise visou à identificar o sistema avaliativo, os critérios previstos, os critérios avaliativos e orientações acerca da avaliação na disciplina de Educação Física. $O$ questionário foi aplicado pelo pesquisador, o qual após agendamento, distribuiu e aguardou as respostas dos três professores de Educação Física. O grupo focal com os estudantes foi realizado com os líderes e um vice-líder das 9 turmas visando compreender a percepção deles sobre a avaliação na disciplina de Educação Física e os critérios utilizados pelos professores. Foram feitos dois grupos focais, um com seis e outro com cinco estudantes. 
O pesquisador, após a autorização da diretora, foi até a sala de aula e convidou os líderes de turma para participarem da pesquisa, sendo que na turma da noite foi convidado um vice-líder para completar os cinco integrantes no grupo focal. A análise de dados foi realizada utilizando os pressupostos de Bardin (2009).

\section{Projeto político-pedagógico}

Ao construirmos os projetos de nossas escolas, planejamos o que temos intenção de fazer, de realizar. Lançamo-nos para diante, com base no que temos, buscando o possível. É antever um futuro diferente do presente. Nas palavras de Gadotti (1994),

todo projeto supõe rupturas com o presente e promessas para o futuro. Projetar significa tentar quebrar um estado confortável para arriscar-se, atravessar um período de instabilidade e buscar uma nova estabilidade em função da promessa que cada projeto contém de estado melhor do que o presente. Um projeto educativo pode ser tomado como promessa frente a determinadas rupturas. As promessas tornam visíveis os campos de ação possível, comprometendo seus atores e autores. (p. 579)

Nessa perspectiva, o projeto político-pedagógico vai além de um simples agrupamento de planos de ensino e de atividades diversas. O projeto não é algo que é construído e em seguida arquivado ou encaminhado às autoridades educacionais como prova do cumprimento de tarefas burocráticas. Ele é construído e vivenciado em todos os momentos, por todos os envolvidos com o processo educativo da escola.

Pelo projeto se busca um rumo, uma direção. É uma ação intencional, com um sentido explícito, com um compromisso definido coletivamente. Por isso, todo projeto pedagógico da escola é, também, um projeto político por estar intimamente articulado ao compromisso sociopolítico com os interesses reais e coletivos da população majoritária. É político no sentido de compromisso com a formação do cidadão para um tipo de sociedade.

Marques (1990) afirma que as palavras político e pedagógico têm assim uma significação indissociável. Neste sentido é que se deve considerar o projeto políticopedagógico como um processo permanente de reflexão e discussão dos problemas da escola, na busca de alternativas viáveis à efetivação de sua intencionalidade, que não é descritiva ou constatativa, mas é constitutiva.

Veiga (2002) afirma que o PPP tem a ver com a organização do trabalho pedagógico em dois níveis: como organização da escola como um todo e como organização da sala de aula, incluindo sua relação com o contexto social imediato, procurando preservar a visão de totalidade. Nesta caminhada será importante ressaltar que o PPP busca a organização do trabalho pedagógico da escola na sua globalidade.

Considerando avaliação como parte do compromisso que assegura a eficácia e eficiência das propostas, cabe também salientar pontos importantes: "primeiro, a avaliação é um ato dinâmico que qualifica e oferece subsídios ao Projeto PolíticoPedagógico. Segundo, ela imprime uma direção às ações dos educadores e dos educandos" (Veiga, 2002, p. 9).

Nesse sentido, a avaliação orientará o rumo do processo, em que o professor traçará seus objetivos de acordo com o PPP para acompanhar o processo de ensino e de aprendizagem e verificar os avanços e as dificuldade dos estudantes. 
Cabe salientar que a avaliação não será utilizada como meio de exclusão dos estudantes, e sim de oportunizar o melhor desenvolvimento dos mesmos: "Deve favorecer o desenvolvimento da capacidade do aluno de apropriar-se de conhecimentos científicos, sociais e tecnológicos produzidos historicamente e deve ser resultado de um processo coletivo de avaliação diagnóstica (Veiga, 2002, p. 9).

Para que ocorra a consolidação da proposta expressa no PPP precisamos compreender e refletir sobre suas ações, e utilizar da avaliação como método de identificação da situação em que se encontra o processo de ensino e de aprendizagem, para poder identificar e corrigir possíveis dificuldades encontradas.

\section{Educação física no ensino médio}

Segundo a lei n. 9.394/1996, art. 24, inciso I, o ensino médio deve contar com uma carga horária de 800 horas em no mínimo 200 dias letivos. Em 2017 houve uma reforma no ensino médio, agora podendo contar com colégios integrais que irão oferecer cursos profissionalizantes. As alterações realizadas na lei n. 9.394, de 20 de dezembro de 1996, implicam em que a própria instituição oferte formação técnica a esses educandos, que seja aprovado previamente pelo Conselho Estadual de Educação, homologada pelo Secretário Estadual de Educação e certificada pelos sistemas de ensino. (Brasil, 1996).

Esta reforma buscou requalificar o ensino médio, inclusive o que será lecionado, e até mesmo o aumento da carga horária. De acordo com a lei n. 13.415, de 16 de fevereiro de 2017, a carga horária aumentou, passando a ter 1.400 horas, em um prazo de cinco anos para suprir esta carga horária, sendo que tenha 1.000 horas anuais a partir de 2 de março de 2017 como consta no $\S 1^{\circ}$ da lei $n$. 13.415 de 16 de fevereiro de 2017. (Brasil, 2017).

Há várias discussões acerca do que deverá ser lecionado no ensino médio e de que forma o currículo será aplicado, principalmente referente ao ensino médio noturno, no qual se encontram estudantes que frequentam este período, pois trabalham durante o dia. Verenguer (1995) afirma que "deve-se propiciar aos alunos do ensino médio: pensar suas possibilidades motoras e a influência que recebem do contexto social, ampliando seu repertório cultural sem deixar de lado, naturalmente, experiências motoras que propiciem sua melhora e/ou refinamento" (p. 73).

Nahas (1997) já tem uma posição diferente sobre esta questão. Ele sugere que a Educação Física tenha uma função de promover um estilo de vida ativo. Sendo assim o objetivo é ensinar conceitos básicos de aptidão física e saúde, além de oferecer vivências diversificadas, levando seus alunos a optarem por um estilo de vida mais ativo, contrapondo também com a proposta do autor citado abaixo.

Tedeschi (1997) destaca que o ensino médio sempre privilegiou a prática do esporte deixando de lado os demais componentes da cultura corporal. Costa (1997), por outro lado, acredita que os alunos do ensino médio possuem uma opinião formada sobre a Educação Física, sendo ela boa ou ruim, caracterizada por experiências passadas, ou seja, se o aluno obteve experiências de sucesso e prazer, será diferente sua opinião sobre essa disciplina em relação aos alunos que tiveram experiências de insucesso ou de exclusão das aulas. 
O Coletivo de Autores (2012) apresenta uma organização da Educação Física escolar em quatro ciclos, no qual o quarto ciclo se encontra o ensino médio: "É o ciclo de aprofundamento da sistematização do conhecimento. Nele o aluno adquire uma relação especial com o objetivo, que lhe permite refletir sobre ele" (Coletivo de Autores, 2012, p. 36).

Esses autores apontam diversos conteúdos da Educação Física: jogo; esporte; capoeira; ginástica e dança. Cada um dos conteúdos possui objetivos voltados ao seu respectivo ciclo de escolarização do processo de ensino-aprendizagem. Sendo assim o jogo no ensino médio precisa conter "jogos cujo conteúdo implique o conhecimento sistematizado e aprofundado de técnicas e táticas, bem como da arbitragem dos mesmos" (Coletivo de Autores, 2012, p. 69). Os conteúdos são tratados de forma simultânea e o conhecimento e seu pensamento serão trabalhados de forma espiralada e ampliada. Por fim, o Coletivo de Autores (2012) afirma que os jogos devem propiciar uma "prática organizada conjuntamente entre escola/comunidade" (p. 69).

\section{Avaliação na educação física}

A Educação Física vem se modificando ao longo do tempo e várias metodologias foram desenvolvidas, com necessidades e propósitos. Essas concepções foram classificadas e apresentadas por Ghiraldelli (2003) como higienista, militarista, pedagogicista e competitivista. Segundo Ghiraldelli (2003) a educação higienista está voltada a saúde, tornando seu aluno mais saudável e tendo em vista a formação de homens e mulheres sadios e fortes. Quanto à educação Física militarista não se resume em uma prática militar de preparo físico. Esta concepção busca aplicar à sociedade padrões de comportamentos, podendo assim distribuir melhor homens e mulheres em atividades sociais e profissionais.

Para Ghiraldelli (2003) as concepções citadas anteriormente não abordam a Educação Física como uma prática educativa voltada ao currículo da escola. A Educação Física pedagogicista por outro lado está direcionada a educação do movimento, sendo esta, a única forma de uma educação integral.

Ghiraldelli (2003) afirma que a Educação Física competitivista tem como característica principal a competição e da superação individual e assim como a militarista está voltada a uma elitização social: "A Educação Física competitivista volta-se, então, para o culto do atleta-herói; aquele que a despeito de todas as dificuldades chegou ao pódio" (p. 20).

Percebemos que cada concepção tem um objetivo: valorizar o movimento, a saúde e o saber fazer. Essas perspectivas limitam o processo avaliativo, de modo a avaliar apenas o saber fazer e não o processo de ensino e aprendizagem: "Essa perspectiva limitada do sentido e da finalidade da avaliação pode, ainda, ser exemplificada nas consequências pedagógicas quando a referência para a avaliação é a aptidão física, e os critérios decorrem do sistema esportivo de alto rendimento" (Coletivo de Autores, 2012, p. 97).

Para o Coletivo de Autores (2012) o movimento renovadores surgiu entre os anos 1970 e 1980, destacando a psicomotricidade que, pela teoria do movimento, utilizou a atividade física como instrumento de mudança de hábitos, ideias e sentimentos. Coletivo de Autores (2012) apresenta entre os movimentos renovadores o humanista, que surgiu como uma crítica às psicologias comportamentalistas: 
Os movimentos renovadores da Educação Física, do qual faz parte o movimento dito "humanista", na pedagogia se caracterizam pela presença de princípios filosóficos em torno do ser humano, sua identidade e valor, tendo como fundamento os limites e interesses do homem e surge como crítica a correntes oriundas da psicologia conhecidas como comportamentalistas. (Coletivo de Autores, 2012, p. 55)

Com estes novos movimentos renovadores na Educação Física foi possível perceber a mudança das perspectivas, antes voltada à saúde, esporte e saber fazer, e que hoje está direcionada ao processo ensino-aprendizagem. Função esta que aprimora os processos avaliativos: "A proposta de avaliação do processo de ensino-aprendizagem da Educação Física deve, portanto; levar em conta a observação, análise e conceituação de elementos que compõem a totalidade da conduta humana e que se expressam no desenvolvimento de atividades" (Coletivo de Autores, 2012, p. 102). Portanto, o objetivo da avaliação é "diagnosticar qual a posição do aluno em determinado momento em relação aos objetivos fixados e por que tem ou não dificuldades de progredir" (Sousa, 1993, p. 148).

Sousa (1993) afirma que o processo avaliativo não medirá o seu aluno diante de notas, porém terá ênfase no diagnóstico dos avanços e das dificuldades, e o professor junto com o aluno buscará soluções cabíveis para sanar as dificuldades: "As práticas avaliativas produtivo-criativas e reiterativas buscam imprimir à avaliação uma perspectiva de busca constante da identificação de conflitos no processo ensino-aprendizagem, bem como a superação dos mesmos, através do esforço crítico e criativo coletivo dos alunos e as orientações do professor" (Coletivo de Autores, 2012, p. 102).

Deste modo, a avaliação irá revisar a proposta do educador, e observar se os estudantes estão compreendendo o conteúdo, como também verificar se a metodologia e prática utilizada pelo professor estão resultando na aprendizagem. Portanto, se os estudantes não estão conseguindo compreender o conteúdo proposto a eles, a dificuldade é dos alunos, da metodologia trazida pelo professor, ou de ambos? Sendo assim o processo avaliativo está diretamente ligado ao processo de ensino e de aprendizagem.

Por outro lado, Masetto (2003) afirma que

o processo avaliativo ganha uma dimensão diagnóstica porque permite verificar se a aprendizagem está sendo alcançada ou não, e o porquê; uma dimensão prospectiva quando oferece informações sobre o que se fazer dali por diante para um contínuo reiniciar do processo de aprendizagem até atingir os objetivos finais; e uma dimensão de avaliação formativa enquanto acompanha o aprendiz durante o todo o processo, e em todos os momentos. (p. 150)

Para Haydt (1991) a avaliação tem cinco propósitos: avaliar para conhecer os alunos; determinar se os objetivos previstos para o processo ensino-aprendizagem foram ou não atingidos; aperfeiçoar o processo ensino-aprendizagem; diagnosticar as dificuldades de aprendizagem; promover os alunos. Para que todos esses propósitos e objetivos sejam alcançados é preciso de técnicas e instrumentos.

Um dos instrumentos mais tradicionais de se avaliar são as provas escritas. Segundo Gil (2008) ela decorre de duas maneiras, a dissertativa, a qual utiliza de perguntas que exigem uma resposta mais longa do aluno e possibilita o desenvolvimento 
livre do estudante, e a prova de perguntas curtas, no qual o professor irá trazer questões abertas formuladas de tal modo que limitem a extensão e o gênero das respostas. Uma prova discursiva é aquela pela qual o professor "apresenta temas ou questões para que os alunos discorram sobre elas ou respondam a elas. Constituem um dos mais tradicionais instrumentos adotados para a avaliação da aprendizagem". Este instrumento é adequado para avaliar "o raciocínio lógico dos estudantes; a capacidade de analisar, hierarquizar e sintetizar as ideias; a justificativa das opiniões e a clareza de expressão." (Gil, 2008, p. 255). Porém, podemos destacar pontos negativos como "o excessivo gasto de tempo na correção; a influência da subjetividade do professor; a dificuldade para avaliar o aprendizado de toda matéria; a interpretação inadequada de seus propósitos pelos estudantes e a dificuldade para fornecer feedback específico" (Gil, 2008, p. 255).

Para Gil (2008) na prova objetiva há perguntas breves com respostas exatas, as respostas nessas provas são compostas por sinal, número, palavras ou frases. A elaboração desta avaliação permite que seja possível corrigir por meio de uma chave, assim possibilitando ao professor, atingir os mesmos resultados, sendo comum este instrumento em vestibulares e concursos públicos.

Este instrumento contribui para um julgamento parcial, garantindo uma correção rápida e proporcionando feedback aos estudantes, assim como possibilitar a comparação entre as turmas e avaliação do trabalho docente. No entanto, "também se alega que inibe a criatividade dos alunos, que os desestimula a escrever, que é uma loteria, que degrada o trabalho escolar etc" (Gil, 2008, p. 258).

O processo de avaliação precisa contar também com a autoavaliação, processo este que confronta o estudante para que se perceba, reflita sobre o conhecimento adquirido, e possa assim tomar medidas que proporcionem o desenvolvimento da aprendizagem: "Uma modalidade simplista de autoavaliação consiste em pedir a cada aluno que atribua a si mesmo uma nota em determinada disciplina, nota esta que poderá ser considerada na composição da nota final" (Gil, 2008, p. 253).

Por último, Gil (2008) cita a prova oral, que já foi muito utilizado, no entanto hoje é bem mais raro presenciar este tipo de avaliação, a não ser com estudantes que portam algum tipo de necessidade especial: "Também podem ser utilizadas para verificar as habilidades para o desempenho de tarefas que exijam locução, como de entrevistadores, intérprete ou guia de turismo, por exemplo" (p. 263).

De acordo com Masetto (2003) podemos acrescentar como técnica avaliativa o registro de incidentes críticos. Dedica-se a uma técnica de observação. Do qual está em pauta as atitudes e habilidades dos educandos.

O diário de curso consiste em mais uma técnica de avaliação apontada por Masetto (2003) em que envolve o registro. Nesta avaliação o aluno irá realizar uma descrição das ações de seus colegas, professores e tudo mais que achar significativo. Percebemos o quão vastas são as possibilidades de instrumentos avaliativos que o docente tem ao seu dispor. Porém, o docente não irá escolher a que mais lhe convém, ou utilizar todos eles.

\section{Análise e discussão dos dados}

A presente pesquisa foi realizada com três professores de Educação Física, sendo dois do gênero masculino e um feminino. $P 2^{3}$ e P3 se formaram na Unesc, e P1 na

${ }^{3}$ Utilizamos esse código para identificar os professores e manter o anonimato.

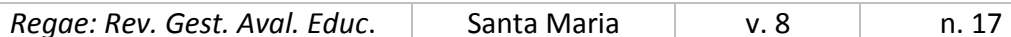

Pub. contínua 2019

p. $1-15$ 
Esucri. Dois colaram grau até seis anos e P3 há 26 anos e tem formação em Educação Física licenciatura e bacharelado, enquanto os outros dois professores possuem formação em Educação Física licenciatura. Quanto ao tempo de atuação no ensino médio, dois tem somente três anos e P3 tem 18 anos. Dos três professores dois possuem pós-graduação, o P2 em uma instituição à distância e a professora P3 em um curso presencial. Quanto a formação continuada acerca da avaliação todos declararam já ter cursado alguma atividade.

Participaram do grupo focal dez estudantes do ensino médio com idade entre 15 a 20 anos. Dentre eles seis do gênero feminino e quatro do gênero masculino. Quatro se encontram no $1^{\circ}$ ano do ensino médio, três no $2^{\circ}$ ano e três no $3^{\circ}$ ano. Foram apresentados sete pontos para discussão nos dois grupos focais com os estudantes realizados na sala de informática da escola.

A análise do PPP da escola pesquisada foi realizada baseada nos seguintes pontos: sistema de notas utilizado, conceito de avaliação, utilização da autoavaliação, avaliação na disciplina de Educação Física, possibilidades de realizar a avaliação e definição de critérios avaliativos.

Identificamos no PPP o item que trata da avaliação, o qual possui apenas uma página. $O$ texto inicia informando que a escola passou a seguir as orientações da resolução n. 183/2014/CEE/SC a partir de 2015. Esta resolução trata da avaliação, aceleração de estudos, avanços nos cursos ou séries/anos, classificação e reclassificação, conselho de classe, revisão de resultados e dos recursos e sua tramitação.

Quanto aos instrumentos avaliativos utilizados no ensino médio todos afirmaram que utilizam trabalhos em sala, pesquisa, avaliações teóricas e avaliação prática. O P3 utiliza, "avaliação escrita dos conteúdos, trabalhos em sala de aula, avaliação prática do conteúdo, trabalhos de pesquisa e autoavaliação"

Percebemos que os professores utilizam quatro instrumentos de avaliação no decorrer de suas aulas, com o objetivo de completar o quadro de três notas ao final do bimestre. Podemos identificar que a avaliação está presente a todo momento na aula, sendo ela para diagnosticar o conhecimento do estudante a até mesmo favorecer 0 desenvolvimento do aluno assim como o processo ensino-aprendizagem.

$\mathrm{Na}$ percepção dos estudantes, de todas as turmas do ensino médio os professores de Educação Física utilizam mais a avaliação teórica. O segundo tipo de avaliação mais citado foram os trabalhos, seguido de avaliação prática e da participação do estudante. Fica evidente que não são muito diversificados os tipos de avaliação.

Esse resultado, da prova ser o instrumento mais utilizado na disciplina de Educação Física no ensino médio, está em consonância com a pesquisa de Ferreira (2017), que afirma que a avaliação escrita é também o instrumento mais utilizado no ensino superior pela maioria dos professores.

O estudante (E94) cita "comportamento, uniforme e participação." Cabe destacar que a participação, uniforme e comportamento podem ser critérios avaliativos e não um instrumento ou tipo de avaliação, pois, segundo Triviños (2001 apud Ferreira 2010) critério é um conjunto de ideias, princípios, crenças, necessidades, objetivos, que nos ajudam a atuar em determinado campo da realidade: "Poderíamos dizer de forma

${ }^{4}$ Utilizamos esse código para identificar os estudantes e manter o anonimato.

\begin{tabular}{l|l|l|l|} 
Regae: Rev. Gest. Aval. Educ $\quad$ Santa Maria & v. 8 & n. 17
\end{tabular}

Pub. contínua 2019

p. 1-15 
simplificada que critérios de avaliação são princípios que tomamos como referência para julgar alguma coisa e têm como sinônimo, parâmetros, padrões de julgamento, padrão de referência, indicadores, entre outros" (Ferreira, 2010, p. 100).

Quanto ao sistema avaliativo está previsto no PPP que as notas do ensino fundamental e do ensino médio deverão ser registradas pelo professor no diário online, assim como os procedimentos avaliativos, recuperação de estudos e presença dos estudantes. Os registros dos resultados serão bimestrais, devendo ser expresso de forma numérica de um a 10 , com fração de 0,5 . O aluno que não atingir a média igual ou superior a sete pontos, deve realizar uma avaliação paralela.

Dentre os procedimentos avaliativos é prevista a utilização de: avaliação sem consulta com uma recuperação paralela; trabalhos com consulta sem recuperação paralela e interpretação.

Nas avaliações escritas é obrigatória a utilização de um cabeçalho identificando a escola, professor, data, turma e peso da prova, assim como em cada questão. Também está previsto como um procedimento avaliativo a exigência de que os trabalhos e provas sejam escritos com caneta azul ou preta.

Quanto à utilização da autoavaliação, P3 citou que "acho necessário que os alunos saibam se avaliar e também o professor." Diferente dos demais, ela utiliza a autoavaliação para avaliar o seu trabalho, o que é de extrema importância.

Este processo de avaliação possibilita o estudante se perceber e se reconhecer diante de seu desenvolvimento da aprendizagem. Segundo Gil (2008), "autoavaliação é o processo pelo qual as pessoas se apercebem do quanto aprenderam e em que medida se tornaram capaz de propiciar a si mesmas informações necessárias para 0 desenvolvimento da aprendizagem" (p. 253).

Quanto à autoavaliação, oito dos 10 estudantes, disseram que já fizeram e sabem o que é. Dentre os estudantes que sabem o que é uma autoavaliação e já o fizeram, o estudante (E9) disse que "é uma forma do professor avaliar e nós nos avaliar, nosso próprio desempenho, comportamento e participação da aula."

Outro estudante tem uma opinião controversa acerca da autoavaliação e diz que (E10) "nem sempre o que nós avaliamos é a nota que a professora vai colocar". Durante o debate o mesmo afirmou que a autoavaliação não é eficaz, pois o professor acaba dando a verdadeira nota para o aluno, diferente da autoavaliação realizada. Outro estudante completou dizendo que (E2) "essa avaliação pode ver se o aluno está mentindo ou não, vai da questão de sinceridade do aluno." Por fim, evidenciamos que a maioria já fez autoavaliação nas aulas de Educação Física, porém alguns não acreditam na sua eficácia.

Esse é um resultado relevante da pesquisa, pois a autoavaliação é um aspecto de importante para o processo avaliativo. Segundo Masetto (2003) esta avaliação "exige o desenvolvimento de habilidades como a de observar-se a si mesmo, comparar e relacionar seu desempenho com os objetivos propostos; atitudes como honestidade pessoal para reconhecer tanto seus sucessos como suas falhas" (p.154). 
Quanto aos critérios utilizados para avaliar os estudantes, todos os professores citaram a participação, seguido por, (P2) "desempenho na prática, prova e trabalhos". Diferente dos demais, o professor P3 utiliza o "comportamento e analiso se o aluno sabe fazer." Percebemos que os critérios avaliativos dos professores se assemelham, porém, é evidente a falta de discernimento do que são instrumentos e critérios avaliativos.

Os estudantes citaram seis critérios de avaliação utilizados pelos professores de Educação Física: participação, uniforme, capacidade física, trabalhos/provas, comportamento e frequência. Os estudantes em geral têm conhecimento dos critérios de avaliação utilizados por seus professores, sendo que a participação foi a mais citada (três estudantes).

Perante aos critérios avaliativos podemos destacar que suas determinações surgem de dois pontos principais: o primeiro destes pontos é a "qualitativa, se refere à descrição do que deve ser alcançado em termos de habilidades motoras, conhecimento e atitudes. Nesse caso, são critérios diretamente ligados à própria qualidade de cada desempenho" (Depresbiteris, 1989, p. 72). O segundo ponto principal para se definir os critérios avaliativos é de origem quantitativa, ou seja, sua habilidade motora, conhecimento e atitudes são representados em valores numéricos.

Quanto aos critérios o PPP aponta a utilização da participação efetiva nas aulas, frequência, pontualidade, estar em dia com seus materiais e disciplina, e ainda que os critérios avaliativos deverão ser discutidos em conselhos de classe pois, "o Conselho de Classe é a instância deliberativa integrante da estrutura das unidades escolares e tem sob sua responsabilidade" (PPP, 2018, p. 2).

Quanto à forma de selecionar os critérios avaliativos, P1 afirma: "a partir do PPP." O professor P2 utiliza: "documentos que norteiam a avaliação." E o professor P3 segue o: "planejamento, PCNs e base nacional curricular."

$\mathrm{Na}$ pergunta anterior foi possível observar que o critério participação foi citado por ambos os professores, podendo assim identificar que independente da origem dos documentos norteadores para selecionar os critérios avaliativos eles se assemelham.

Ao analisarmos o PPP da escola pesquisada, podemos destacar que "a avaliação do aluno será processual, participativa, formativa e diagnóstica, mediante a verificação da aprendizagem de conhecimentos e do desenvolvimento de competências em atividades de classe e extraclasse, incluídos os procedimentos próprios de recuperação paralela. (PPP, 2015, p. 1).

Como podemos observar, um dos professores cita que define seus critérios avaliativos a partir do PPP, porém quando perguntado o que o PPP da escola aponta sobre a avaliação o professor $\mathrm{P} 1$, o mesmo que seleciona seus critérios avaliativos a partir do PPP, citou que "não foi lido até o momento." O professor P2 cita que "a quantidade de avaliação mínima por bimestre" e o professor P3 "que se deve considerar o que o aluno aprendeu através das mais variadas formas de avaliar."

Podemos observar que cada professor tem um meio de definir seus critérios avaliativos, sendo ele por meio de documentos que abordam a avaliação, quanto a Base Nacional Comum Curricular. Dentre os professores de Educação Física foi possível observar que dois dos três tem conhecimento do que o PPP aborda sobre a avaliação, mas nenhum utiliza o PPP para selecionar seus critérios avaliativos. 
Quanto à participação dos estudantes da elaboração do planejamento, afirmou o professor P1 que "elaboro minhas aulas de acordo com cada turma, sendo assim eles participam."

Podemos perceber que o professor cita que há uma participação, porém em nenhum momento ele afirma que os estudantes opinam em questão ao planejamento, apenas que cada turma possui um planejamento diferente. Os demais professores afirmaram que não participam e completa (P3): "o planejamento é realizado em conjunto com os professores de Educação Física da escola na semana de planejamento no início do ano letivo."

Segundo Luckesi (2001) "o planejamento implica o estabelecimento de metas, ações e recursos necessários à produção de resultados que sejam satisfatórios à vida pessoal e social, ou seja, à consecução dos nossos desejos" (p. 162). Luckesi (2001) diz que tratando do processo ensino-aprendizagem, planejar vai para além de criar metas, o planejar exige um conhecimento seguro do que se deseja com a educação, bem como valores e significados.

Quanto à participação dos estudantes na elaboração do plano de ensino, referente a sugestão de conteúdos e avaliação, foi unânime a resposta de que não há participação. No entanto, dois estudantes citaram que o professor apresentou os conteúdos e objetivos a serem trabalhados na aula, bem como as avaliações sobre o conteúdo. Acrescentou que "não, nunca fizeram, o professor apresenta os objetivos no início da aula, mas nada além de apresentar os temas das próximas aulas" (E4). O PPP não prevê a participação dos estudantes na construção do planejamento.

Quanto à função da avaliação e para que serve o estudante P3 afirmou que seria "para averiguar se realmente o aluno aprendeu os conteúdos desenvolvidos." Já o professor P1 "para saber a evolução e o conhecimento do aluno." O P2 completa dizendo que: "para realizar um diagnóstico do processo ensino-aprendizagem." Os professores têm uma visão convergente acerca das funções da avaliação de averiguar, saber a evolução e diagnóstico, porém para Sousa (1997) há três funções da avaliação, sendo elas: diagnosticar, retro-informar e favorecer o desenvolvimento individual.

Segundo Luckesi (2001) a função da avaliação é propiciar a autocompreensão, motivar o conhecimento, aprofundamento da aprendizagem e auxiliar a aprendizagem. Sendo assim, o ato de avaliar vai além de apenas aplicar testes, tem por objetivo identificar o grau de aprendizado do estudante bem como a eficácia da metodologia utilizada pelo professor quanto o aprofundamento do conhecimento adquirido.

Quanto ao conhecimento da avaliação, todos os dez estudantes disseram saber quando eram avaliados: "Mesmo para os aspectos mais subjetivos, como, por exemplo, participar com interesse, o aluno deverá saber logo de início como, quando e de que modo estará sendo avaliado, para que sua participação e entendimento do processo de ensino e aprendizagem sejam ampliados" (Brasil, 1997, p. 59).

O estudante E4 afirmou que "através do diário online é possível acompanhar as avaliações e suas datas." Ratificando o estudante, o professor, P3, disse que "eles têm acesso online onde veem a agenda das avaliações e na sala de aula também há um manual impresso." O E8 afirmou que "sempre que tem avaliação ou trabalho o professor avisa a data que será realizada, porém a avaliação da participação, o professor avisou apenas no primeiro dia de aula." E3 disse que "se os professores observando não estão avaliando, então não sei o que estão fazendo". 
Segundo Souza (1997) "é a partir da observação, da análise, da reflexão crítica sobre a realidade, pelos sujeitos envolvidos no processo de trabalho, que se estabelecem as necessidades, prioridades e propostas de ação" (p. 127), ou seja, a observação é fundamental para acompanhar o avanço individual de cada aluno assim como definir novas estratégias de ensino. Todos os estudantes concordaram com essa ideia de que a observação é inerente ao processo de avaliação, ou seja, de que o professor precisa ser um excelente observador.

Quanto ao conceito de avaliação o PPP não a expressa claramente, mas indica que a avaliação deve ser processual, participativa, formativa e diagnóstica.

Quanto à importância da avaliação nas aulas de Educação Física P3 afirmou que "a Educação Física é uma disciplina igual as demais, tem conteúdos que são realizados da mesma forma." O professor P2 que, "é importante para "medir" o andamento das aulas" e o professor P1 que "para constar o que o aluno aprendeu durante o ano letivo."

De acordo com a importância da avaliação, é difícil tratar apenas da aula de Educação Física, pois é uma ferramenta utilizada por todos os professores, como cita P3, "a Educação Física tem conteúdos definidos assim como as demais matérias que exigem o aprendizado do estudante, assim como a avaliação para o diagnóstico do seu aprendizado."

Os instrumentos avaliativos buscam verificar se os objetivos propostos pelo programa de ensino foram atingidos, se a metodologia foi adequada, se ocorreu aprendizagem, bem como para ter um feedback e realizar as mudanças e o replanejamento. Cabe destacar que os instrumentos precisam ser elaborados no sentido de possibilitar aos alunos o conhecimento sobre o que, como, onde, quando serão avaliados, e se de forma individual, dupla ou em grupos (Brasil, 1997).

Quanto à função da avaliação na disciplina de Educação Física, a percepção da maioria dos estudantes, oito, evidencia que a avaliação é somente deles e dois apontaram que a avaliação serve para verificar o andamento das aulas.

Para alguns estudantes a avaliação é uma forma de verificar se o aluno aprendeu, de medir o conhecimento, como citou o estudante (E1) "para medir o conhecimento do aluno e ver se ele está adquirindo algum conhecimento". De outro ponto de vista o estudante (E7) citou que "ee o aluno não está aprendendo, é preciso buscar compreender o problema, pois se os alunos não estão aprendendo algo está errado." O estudante E4 afirmou que "para ver se o professor está usando os métodos certos para ensinar os alunos, porque se a maioria dos alunos tirarem nota baixa alguma coisa está errada".

A análise do PPP permitiu identificar que não há especificações de avaliação para a disciplina de Educação Física, somente a ideia geral de avaliação processual, formativa e diagnóstica, aproximada a de Sousa (1997), de que a avaliação tem função de diagnosticar, retroinformar e favorecer o desenvolvimento individual.

Quanto à recuperação para os estudantes que não atingiram a média, dois dos entrevistados explicaram o conteúdo novamente. Dois dos entrevistados realizam uma retomada do conteúdo para que seja possível a realização de uma nova avaliação, enquanto um dos entrevistados aplica uma forma alternativa de recuperar a nota. Cabe destacar que é importante recuperar o conteúdo/aprendizado e a nota. Segundo Sordi 
(2005), "o compromisso com a inclusão do aluno no processo e reversão de sua eventual rota de fracasso é fundamental para a arquitetura de práticas de recuperação que possam dar conta da diversidade dos alunos e seus diferentes capitais culturais, sociais, econômicos. Há que se reconhecer e lidar com essas condições que são determinantes no processo de ensino" (p. 24).

Quanto à realização da recuperação todos os estudantes responderam que é realizada uma avaliação para os estudantes que não obtiveram a média: "A recuperação propicia recuperar a nota, dando oportunidade de o aluno atingir a média” (E4). As recuperações realizadas são de caráter substitutivo, ou seja, a avaliação com a nota maior prevalece. Outro estudante, E2, disse que "dificilmente ocorre uma recuperação, pois todos os alunos atingem a média."

O PPP prevê a realização da recuperação para os estudantes que não atingem a média, bem como a resolução n. 183/2013/CEE/SC, no entanto é provável que os estudantes não a realizam por atingirem a média na disciplina de Educação Física.

Por fim, percebemos como pontos convergentes na triangulação dos dados entre análise do PPP, voz dos professores e estudantes: os instrumentos avaliativos utilizados: avaliação teórica, trabalhos, avaliação prática e recuperação; os critérios avaliativos: participação e comportamento. A utilização da prova de recuperação é realizada por todos, porém a sua utilização não se faz necessário, pois dificilmente um estudante não atinge a média.

Outro ponto convergente quanto ao conhecimento foi sobre quando estão sendo avaliados, Durante o grupo focal os estudantes apresentaram um conhecimento acerca da avaliação, citando a função diagnóstica e verificação da metodologia do professor.

Como pontos diferentes: a autoavaliação foi citada por um professor P3 e alguns estudantes, a mesma é de extrema importância, no entanto, não está prevista no PPP da escola.

Perante as definições dos métodos avaliativos, um professor citou que é a partir do PPP, porém não o leu, os demais citaram documentos que fundamentam a avaliação, porém o PPP afirma que é baseada na resolução 183/2013/CEE/SC e que deve ser discutido tudo no conselho de classe.

\section{Considerações finais}

Percebemos que o PPP da escola pesquisada sugere três possibilidades para avaliar, sendo eles: avaliação escrita sem consulta, trabalho com consulta e interpretação, sendo que a autoavaliação, que possibilita o aluno se perceber perante o processo de aprendizagem e desenvolvimento não está prevista, porém, um dos professores utiliza este instrumento avaliativo. Citou-se, ainda, trabalhos de pesquisa e avaliação prática.

Dos três professores dois utilizam os PCNs e a BNCC para selecionar seus critérios avaliativos, sendo que um deles não soube responder. Tratando do PPP os critérios avaliativos previstos são participação dos estudantes nas aulas, pontualidade e estar em dia com seus materiais, bem como discutir os demais critérios no conselho de classe.

Referente aos critérios avaliativos utilizado pelos professores, evidenciamos a utilização de participação, uniforme, capacidade física, comportamento, frequência e conhecimento adquirido. 
Quanto à construção do planejamento, todos os estudantes afirmaram não haver participação, porém, um professor citou que planeja suas aulas pensando em cada turma individualmente.

Dentre as funções da avaliação, todos os professores apontaram diretamente para o diagnóstico do conhecimento do aluno e destacaram que todos os estudantes sabem quando serão avaliados. Neste sentido todos os estudantes citaram saber quando serão avaliados e ratificaram que a função da avaliação não está voltada ao diagnóstico do conhecimento do estudante, mas também a verificação da didática abordada pelo professor.

No PPP está prevista a utilização de recuperação como obrigatória, sendo aplicada apenas a avaliações sem consulta, para os estudantes que não atingirem a média, porém, sua utilização nas aulas de Educação Física dificilmente ocorre.

No sentido da utilidade acadêmica da pesquisa, serão apresentados e discutidos os resultados com a direção e professores da escola, assim como pensamos que precisamos continuar aprofundando os estudos acerca da temática avaliação do processo ensino e aprendizagem.

\section{Referências}

BARDIN, Laurence. Análise de conteúdo. Lisboa: 70, 2009.

BRASIL. Legislação brasileira, 1996 Disponível em http://www.normaslegais.com.br/legislacao/Lei-13415-2017.htm. Acesso em 17 abr. 2018.

BRASIL. Parâmetros curriculares nacionais. Brasília: MEC, 1997. Disponível em http://portal.mec.gov.br/seb/arquivos/pdf/livro07.pdf. Acesso em 17 abr. 2018.

BRASIL. Parâmetros curriculares nacionais do ensino médio, parte I - bases legais. Brasília: MEC, 2000. Disponível em http://portal.mec.gov.br/seb/arquivos/pdf/blegais.pdf. Acesso em 19 abr. 2018.

BRASIL. Lei n. 9.394, de 20 de dezembro de 1996. Disponível em http://portal.mec.gov.br/seesp/arquivos/pdf/lei9394_Idbn1.pdf. Acesso em 17 abr. 2018.

CONSELHO ESTADUAL DE SANTA CATARINA. Resolução n. 183, de 19 de novembro de 2013. Disponível em http://pesquisas.cee.sc.gov.br/docs_CEE/Resolucao/2013/Resp183_SED\%2000004838_ 2011_revoga\%20a\%20resp.158.pdf. Acesso em 26 maio 2018.

COLETIVO DE AUTORES. Metodologia do ensino de educação física. São Paulo: Cortez, 2012.

COSTA, C.M. Educação física diversificada, uma proposta de participação. SEMINÁRIO DE EDUCAÇÃO FÍSICA ESCOLAR, 4, 1997. Anais ... Escola de Educação Física e Esporte, 1997.

DEPRESBITERIS, Léa. O desafio da aprendizagem: dos fundamentos a uma proposta inovadora. São Paulo: EPU, 1989.

FERREIRA, Robinalva Borges. Avaliação processual: um estudo de caso na Unidade Acadêmica de Ciências Sociais Aplicadas da Universidade do Extremo Sul Catarinense. Criciúma: Unesc, 2010. Disponível em http://livros01.livrosgratis.com.br/cp139151.pdf. Acesso em 18 maio 2018.

GADOTTI, Moacir. Pressupostos do projeto pedagógico. CONFERÊNCIA NACIONAL DE EDUCAÇÃO PARA TODOS, 1994. Anais ... Brasília: MEC, 1994.

\begin{tabular}{|l|l|l|l|l|r|}
\hline Regae: Rev. Gest. Aval. Educ. & Santa Maria & v. 8 & n. 17 & Pub. contínua 2019 & p. 1-15
\end{tabular}


GATTI, Bernardete Angelina. Grupo focal na pesquisa em ciências sociais e humanas. Brasília: Liber Livro, 2005.

GHIRALDELLI, Paulo Jr. Educação física progressista: a pedagogia crítico-social dos conteúdos e a educação física brasileira. São Paulo: Edições Loyola, 2003.

GIL, Antonio Carlos. Didática do ensino superior. São Paulo: Atlas, 2008.

HADJI, Charles. Avaliação desmistificada. Porto Alegre: Artmed, 2001.

HAYDT, Regina Célia Cazaux. Avaliação do processo ensino-aprendizagem. São Paulo: Ática, 1991.

LAKATOS, Eva Maria; MARCONI, Marina de Andrade. Fundamentos de metodologia científica. São Paulo, 2001.

LUCKESI, Cipriano Carlos. Avaliação da aprendizagem escolar. São Paulo: Cortez, 2001.

MARQUES, Mário Osório. Projeto pedagógico: a marca da escola. Revista Educação e Contexto, ljuí, 1990, p. 16-28.

MASETTO, Marcos Tarciso. Competência pedagógica do professor universitário. São Paulo: Summus, 2003.

MASETTO, Marcos Tarciso. O professor universitário em aula. São Paulo: Ed Cortez, 1983.

NAHAS, Markus. Vinícius. Educação física no ensino médio: educação para um estilo de vida ativo no terceiro milênio. SEMINÁRIO DE EDUCAÇÃO FíSICA ESCOLAR, 4, 1997. Anais ... Escola de Educação Física e Esporte, 1997.

OLIVEIRA, Francieli Cardoso. Avaliação nas aulas de educação física no ensino médio em escolas públicas de criciúma. Criciúma. 2014. Disponível em http://repositorio.unesc.net/bitstream/1/3126/1/Francieli\%20Cardoso\%20de\%20Oliveira.pd f. Acesso em 5 jun. 2018.

RIOS, Terezinha Azerêdo. Compreender e ensinar: por uma docência da melhor qualidade. São Paulo: Cortez, 2001.

SOUSA, Clarilza. Prado. Avaliação do rendimento escolar. Campinas: Papirus, 1993.

SOUZA, Sandra Maria Zákia lian. Avaliação escolar e democratização: o direito de errar. In: AQUINO, Julio Groppa (coord.). Erro e fracasso na escola alternativas teóricas e práticas. São Paulo: Summus, 1997, p. 125-137.

SORDI, Mara Regina Lemes. Recuperação da nota, do conteúdo, do conhecimento, do aluno, do homem? Escolhas que fazem a diferença. São Paulo: v 1, no.3, jan./dez, 2005.

TEDESCHI, S. M. Educação física escolar: relatos e propostas. SEMINÁRIO DE EDUCAÇÃO FíSICA ESCOLAR, 4, 1997. Anais ... Escola de Educação Física e Esporte, 1997.

VEIGA, IIma Passos Alencastro. Projeto político-pedagógico da escola: uma construção coletiva. São Paulo: Papirus, 2002.

VERENGUER, Rita Cássia Garcia. Educação física escolar: considerações sobre a formação profissional do professor e o conteúdo do componente curricular no $2^{\circ}$ grau. Revista Paulista Educação Física, São Paulo, v. 9, 1995, p. 69-74. 
Leonan Peres Santana é licenciado em Educação Física da Universidade do Extremo Sul Catarinense.

Endereço: Rua Manoel Porfírio de Melo, SN - 88965-000 - Santa Rosa do Sul - SC Brasil.

Orcid: https://orcid.org/0000-0002-6056-847X

Email: leonanperess@hotmail.com.

Robinalva Ferreira é professora da Universidade do Extremo Sul Catarinense, doutora em Educação pela PUCRS.

Orcid: https://orcid.org/0000-0002-0593-1643.

Endereço: Rua Joaquim Nabuco, 1284/601 - 88803-000 - Criciúma - SC - Brasil.

E-mail: rfe@unesc.net.

Recebido em 13 de outubro de 2018.

Aceito em 21 de dezembro de 2018.

(c) (i) 